Essock, S. M., Hargreaves, W. A., Covell, N. H., et al (1996) Clozapine's effectiveness for patients in state hospitals: results from a randomized trial. Psychopharmacology Bulletin, 32, 683-697.

Moncrieff, J. (2003) Clozapine v. conventiona antipsychotic drugs for treatment-resistant schizophrenia: a re-examination. British Journal of Psychiatry, 183, 161-166.

Rosenheck, R., Cramer, J., Xu, W., et al (1997) A comparison of clozapine and haloperidol in hospitalized patients with refractory schizophrenia. Department of Veterans Affairs Cooperative Study Group on Clozapine in Refractory Schizophrenia. New England Journal of Medicine, 337, 809-8I5.

Wahlbeck, K., Cheine, M., Essali, M. A., et al (2000) Clozapine versus typical neuroleptic medication for schizophrenia. Cochrane Library, issue 3. Oxford: Update Software.

K. H. Kho GGZ Delfland, St Jorisweg 2, 2612 GA Delft, The Netherlands

Author's reply: Dr Karunakaran rightly points out some problems with the interpretation of the Essock et al (1996) naturalistic study of clozapine. However, despite its imperfections, that study deserves some attention, both because it was a large study and because its naturalistic design attempted to replicate the conditions in which clozapine would be given in real clinical practice. The randomisation was not imperfect but unbalanced. The study was indeed not blinded, but this usually favours the experimental treatment, in this case clozapine. Application of the Structured Clinical Interview for DSM-IV confirmed that $95 \%$ of cases had a diagnosis of schizophrenia or schizoaffective disorder. It is indeed difficult to decide what outcome data to use, as I mention in my paper. However, despite the number of crossovers, an intention-to-treat analysis in such a large sample would be expected to show some difference if the effect of clozapine is substantial. In the Kane et al (2001) study I did use intention-to-treat data, but also repeated the analysis with non-intention-totreat data, because of the curiously high drop-out rate in the comparison group.

My analysis was meant to draw attention to the fact that results of different studies are quite discrepant. The largest study to date, and one that appears to be methodologically robust, found only slight differences between clozapine and haloperidol, which are of doubtful clinical relevance (Rosenheck et al, 1997). In this situation simply quoting the results of a meta-analysis may be misleading.

Dr Kho is right to point out that longterm studies find smaller effects. This cannot be attributed to drop-out rates in the Rosenheck et al (1997) study, at least, where the higher drop-out rate in the haloperidol group would tend to produce an inflated difference between clozapine and the comparator drug. We also cannot assume that short-term studies simply measure pharmacological effects and long-term studies are confounded by non-compliance. Drugs may have different short- and longterm pharmacological effects. Short-term studies might be more likely to be confounded by non-specific factors such as differential expectations of treatments.

Essock, S. M., Hargreaves, W. A., Covell, N. H., et al (1996) Clozapine's effectiveness for patients in state hospitals: results from a randomized trial. Psychopharmacology Bulletin, 32, 683-697.

Kane, J., Marder, S. R., Schooler, N. R., et al (200I) Clozapine and haloperidol in moderately refractory schizophrenia: a 6-month randomized and double-blind comparison. Archives of General Psychiatry, 58, 965-972.

Rosenheck, R., Cramer, J., Xu, W., et al (1997) A comparison of clozapine and haloperidol in hospitalized patients with refractory schizophrenia. Department of Veterans Affairs Cooperative Study Group on

Clozapine in Refractory Schizophrenia. New England Journal of Medicine, 337, 809-8I5.

J. Moncrieff Mascalls Park, Rehabilitation Unit, Mascalls Lane, Brentwood, Essex CMI4 5HQ, UK

\section{Parental age difference and schizophrenia}

To offer hypotheses based simply on clinical experience is pathetically out of date. Perhaps it may be allowed, for a moment, in deference to my advancing years.

Fifty years ago, with some other purpose in mind, I surveyed some 370 cases of schizophrenia in young men. It struck me that, with mild but undue frequency, there was a tendency for their parents' ages to be unusual in one of two ways - either by there being a $>10$-year age difference in the couple, or by the mother being older than the father. In decades of practice since, my impression has remained that this association with schizophrenia occurs a little too often to be accidental. Of course, to prove that would have required time, money, thousands of cases, and the inclination to undertake a major statistical enterprise, and none of those was in my reach.

It is therefore gratifying now to find that, at long last, my hypothesis has been solidly supported, albeit inadvertently, by Zammit et al (2003). They demonstrate, in a 26-year follow-up of some 50000 teenagers, that advancing paternal age is a risk factor for schizophrenia, while maternal age is not - the latter being a significant negative finding to which, however, they pay no further attention. Since this means that, compared with the normal population, people with schizophrenia tend to have fathers who are older but mothers who are not, it follows necessarily that the age difference between the parents also tends to be greater than in the general population.

This does away with Zammit et al's hypothesis that advancing paternal age is pathogenic for schizophrenia by virtue of increasing germ cell mutations. There is no need to invoke genetic mutation with age, given the linkage they have uncovered, in passing, between parental age difference and schizophrenia. A more economical hypothesis is that to be born to a statistically off-centre parental couple is a risk factor for schizophrenia - or, in more ordinary language, there is some psychological risk in being the child of an odd couple.

Are there other social oddities waiting to be identified statistically in schizophrenogenic couples?

Zammit, S., Allebeck, P., Dalman, C., et al (2003) Paternal age and risk for schizophrenia. British journal of Psychiatry, 183, 405-408.

H. Bourne Via P. De Cristofaro 40, 00I36 Roma, Italy

Authors' reply: Dr Bourne suggests that as advancing paternal, but not maternal age is associated with schizophrenia, then people with schizophrenia tend to have fathers who are older than the normal population, but mothers who are not. This is incorrect. In our study, as others have previously shown, advancing maternal age is associated with schizophrenia, but this association can be explained by paternal age, a consequence of the fact that there is strong correlation between parental ages.

Dr Bourne makes an interesting point, however, based on his observations in clinical practice that large differences in parental ages may result in some sort of psychological risk factor for schizophrenia in the offspring. In fact, the absolute difference between parental ages in our study is associated with schizophrenia in the crude analysis, but this association is eliminated after adjusting for the effects of paternal age (Table 1). As paternal age increases, 